\title{
To screen or not to screen? Let the competition decide
}

\author{
Nikolaos I. Papanikolaou* \\ Bournemouth University \\ Department of Accounting, Finance \& Economics
}

\begin{abstract}
We develop a model of spatial competition to explore how changes in the market structure affect the incentives of banks to screen loan applicants. We take a post-crisis perspective that treats the number of banks as exogenous. Our findings reveal that the relaxation of competition distorts banks' incentives to invest in screening.
\end{abstract}

Keywords: financial crisis; bank competition; market structure; screening. JEL Classification: D40; D82; G21.

${ }^{*}$ Correspondence to: Bournemouth University, Faculty of Management, Business School, Department of Accounting, Finance \& Economics, Executive Business Centre, 89 Holdenhurst Road, Bournemouth, BH8 8EB, United Kingdom; Tel.: +44 (0) 1202 968769; E-mail address: npapanikolaou @bournemouth.ac.uk 


\section{Introduction}

The late 2000s financial meltdown dramatically transformed the market conditions in the banking sector. A new landscape has been shaped due to the numerous mergers and acquisitions, which occurred in the wake of the crisis. In this context, many troubled banks either gone bankrupt or received financial assistance in the form of bailouts, which further fed the transformation of the structure of the banking market. As Calderon and Schaeck (2016) point out, financial crises spawn several reforms in banking such as recapitalisations, consolidations, and assisted failures, which substantially affect the degree of competition.

In view of these profound changes, a relationship which is once again at the forefront of academic and policy debates is that between market structure and banks' incentives to screen loan applicants. We examine this relationship from a theoretical viewpoint deviating from the bulk of the relevant literature which takes a pre-crisis perspective assuming that the market structure is endogenous in the sense that it is determined by the entry decisions as dictated by the profitability in the sector. In our model setup, we take a post-crisis perspective and treat the number of banks as exogenous on the basis of the following two factors. First, the various government interventions in the form of bailouts, assisted failures, and non-market-based consolidations, which have been the key determinants of the banking market structure in the aftermath of the crisis. And, second, the fact that the banking industry has been subjected to heavy regulation all the years following the crisis. On the whole, the number of banks in the market is thought of as a policy makers' decision variable in our analysis.

The rest of the paper is structured as follows. Section 2 lays out the basic model of interbank competition in the credit market with banks engaged in screening activity. Section 3 characterises the equilibrium and discusses the results and the key implications. Section 4 summarises the paper and concludes.

\section{The model}

We consider a model of spatial competition à la Salop (1979) with two classes of players: banks and entrepreneurs. Both are risk-neutral and live for one period, which is composed of Stage 1 and Stage 2.

Entrepreneurs are located symmetrically around a circle of length 1 and their total mass is normalised to 1. Each entrepreneur is endowed with a project that requires an investment of one 
unit of money. No initial wealth is assumed so that if a project is to be initiated, entrepreneurs must obtain credit from banks. ${ }^{1}$ A project either succeeds with probability $p_{\theta} \in(0,1]$ yielding a stochastic return $R\left(p_{\theta}\right)>1$, or fails with $1-p_{\theta}$ and returns nothing. The parameter $\theta$ describes entrepreneurs' type and takes the following two values: $\{h, l\}$, where $h$ stands for high- and $l$ for low-quality projects. It, therefore, holds that $p_{h}>p_{l}$ and $R\left(p_{h}\right)>R\left(p_{l}\right)>1$, implying that $p_{h} R\left(p_{h}\right)>p_{l} R\left(p_{l}\right)$, i.e., the expected returns of a type- $h$ project are always higher.

The fraction of entrepreneurs with high-quality projects equals to $q(0<q<1)$, where $q$ is common knowledge. That is, both parties know that in each point of the circle's periphery there is a mass $q$ of entrepreneurs with $h$-type projects and a mass (1-q) of entrepreneurs with $l$-type projects. The two-point distribution of $\theta$ is assumed to be public information. However, $\theta$ itself is observable only to entrepreneurs in the beginning of Stage 1 . This means that entrepreneurs are aware of the quality of their own projects, while this information is not known to banks.

Each entrepreneur expresses his preference over a particular type of bank loan by travelling along the circumference at a per length transportation cost $\tau_{\theta}>0$. Hence, preferences are assumed to be sufficiently heterogeneous to allow the relocation of entrepreneurs on the circle. ${ }^{2}$ The distance $d_{\theta}>0$ that an entrepreneur covers to reach a bank is a measure of his disutility to buy a less-than-ideal product. Subsequently, the total cost of buying one unit of money equals to the sum of the lending rate increased by the total transportation cost $\left(\tau_{\theta} d_{\theta}\right)$ the entrepreneur is required to sustain to reach the bank of his preference.

The market consists of $n \geq k$ banks, which, like entrepreneurs, are also symmetrically distributed on the unit circle. Banks are profit maximisers and compete in prices, i.e., loan interest rates. ${ }^{3}$ Banks are faced with an informational problem in their lending decision as they do not know the exact type of applicants and thus the quality of the proposed projects. They, therefore, proceed to screen entrepreneurs to obtain their type. Since screening is a costly activity, a bank is capable of identifying the type of entrepreneurs at a cost $e \in(0,1]$ per unit invested. A higher $e$ corresponds to

\footnotetext{
${ }^{1}$ The term 'entrepreneurs' is, therefore, used interchangeably with the terms 'borrowers' and 'applicants' throughout the paper.

${ }^{2}$ The idea behind this is that entrepreneurs incur some disutility by conducting business with a bank that is not of their type.

${ }^{3}$ We do not model competition on the deposit market assuming that the supply of deposits is perfectly elastic at an interest rate that is normalised to zero.
} 
a higher screening cost, or, alternatively, to a more extensive screening effort. We assume that screening is non-contractible, so that banks cannot sell it to their customers as service; also, that the signal received is strictly proprietary in that it is not observable to any other bank in the market. Additionally, screening technology is perfect in the sense that the signal is not noisy. After distinguishing high- from low-quality projects, banks offer entrepreneurs a loan rate $r_{\theta}$ chosen from the set $\left\{r_{l}, r_{h}\right\}$. By being offered distinct rates, entrepreneurs learn the type which has been assigned to them and travel to the bank that satisfies their type to apply for credit.

It is important at this point to make a distinction between transaction and relationship banking. ${ }^{4}$ The former type of banking involves arm's length transactions with borrowers rather than longterm relationships (Boot and Thakor, 2000). This business model treats each loan transaction as a single deal and focuses on the risk entailed in a loan contract. Also, under transaction-based banking practices, the price of the service rather than the relationship that the firm holds with the financial intermediary is the means of attracting a steady stream of business. Studies that shed the spotlight on this form of banking focus on a single banking service paying little or no attention on the synergies between different services, assume homogeneous banks in the sense that banks have no prior information on the risk profile of loan applicants, and examine the acquisition of 'hard' instead of 'soft' information. Our model combines all these features and, hence, our study falls into the area of transaction-based banking.

On the other hand, relationship banking is mainly focused on small business lending. It refers to the provision of a variety of financial services towards the establishment of long-term relationships of (mainly) small banks with customers through multiple interactions. Loans are packaged with other services so that the relationship with a borrower has a marketing value for the bank and, as such, the bank needs to consider the overall cost of rejecting a loan when choosing the optimal screening effort. ${ }^{5}$

Our model can be extended to a relationship-banking environment in two ways. First, if we assume a multi-product (instead of a mono-product) banking market where both loans and deposits are offered. In such a case, relationship banking can be examined on a stand-alone basis. Second, if we distinguish between incumbent and de novo banks where the former institutions lend to the

\footnotetext{
${ }^{4}$ We thank an anonymous reviewer for this suggestion.

${ }^{5}$ Bolton et al. (2013) provide an excellent discussion of the similarities and differences between relationship and transaction-based banking.
} 
same business for a second time and, hence, obtain an informational advantage compared to the latter institutions. In this case, relationship banking and transaction-based banking can be can simultaneously examined. Both extensions are left for further research.

\section{Equilibrium}

At Stage 1, banks screen entrepreneurs and reveal their type. Banks then compete in the credit market by simultaneously making their price offers to entrepreneurs as appropriate. At Stage 2, entrepreneurs observe the loan rates and travel to the bank that offers the contract that is compatible with their type.

The equilibrium solution is obtained by backward induction. For any given $r_{\theta}$, the expected net return of a type- $\theta$ entrepreneur is:

$$
p_{\theta}\left[R\left(p_{\theta}\right)-r_{\vartheta}\right]-\tau_{\theta} d_{\theta}
$$

An entrepreneur applies for credit only if his expected net profit is non-negative:

$$
p_{\theta}\left[R\left(p_{\theta}\right)-r_{\theta}\right]-\tau_{\theta} d_{\theta} \geq 0 \Leftrightarrow d_{\theta} \leq \frac{p_{\theta}\left[R\left(p_{\theta}\right)-r_{\theta}\right]}{\tau_{\theta}}
$$

Since $d_{\theta}>0$, it holds that $\frac{p_{\theta}\left[R\left(p_{\theta}\right)-r_{\theta}\right]}{\tau_{\theta}}>0$. Both $p_{\theta}$ and $\tau_{\theta}$ are larger than zero, and, hence, $R\left(p_{\theta}\right)$ $r_{\theta}>0$, i.e., $R\left(p_{\theta}\right)>r_{\theta}$. This condition stands for the project's viability constraint and shows that the return of an investment project must always outweigh the lending cost. In fact, this condition ensures that eq. (2) is not violated.

Assuming that eq. (2) holds with equality, we obtain:

$$
d_{\theta}=\frac{p_{\theta}\left[R\left(p_{\theta}\right)-r_{\theta}\right]}{\tau_{\theta}}
$$


Eq. (3) shows that it is not profitable for any entrepreneur to apply for a loan beyond $d_{\theta}$. Since entrepreneurs have been informed the type that has been assigned to them in the beginning of Stage 2 when banks made them a price offer (either $r_{h}$ or $r_{l}$ ), we can extract the following equations:

$$
\begin{gathered}
d_{h}=\frac{p_{h}\left[R\left(p_{h}\right)-r_{h}\right]}{\tau_{\theta}} \\
d_{l}=\frac{p_{l}\left[R\left(p_{l}\right)-r_{l}\right]}{\tau_{\theta}}
\end{gathered}
$$

Our focus is on symmetric Nash equilibrium in the loan market. That is, we do not examine collusive equilibria as those sustainable with trigger strategies. Without loss of generality, we assume that a typical bank $j$ offers a rate $r_{\theta}^{j}, j=1,2, \ldots, n$ and that $\tau_{\theta}$ is small enough (but not equal to 0 ) for the banking market to be wholly covered. In this scheme of things, bank $j$ is located equidistantly between banks $j+1$ and $j-1$ that charge $r_{\theta}^{j+1}$ and $r_{\theta}^{j-1}$, respectively. An entrepreneur of type- $\theta$ located at a distance $d_{\theta} \in(0,1 / n]$ from bank $j$ is indifferent between borrowing from $j$ and borrowing from its nearest neighbour, say $j+1$, if:

$$
p_{\theta}\left[R\left(p_{\theta}\right)-r_{\theta}^{j}\right]-\tau_{\theta} d_{\theta}=p_{\theta}\left[R\left(p_{\vartheta}\right)-r_{\theta}^{j+1}\right]-\tau_{\theta}\left(\frac{1}{n}-d_{\theta}\right)
$$

Eq. (4) is the indifference condition, which indicates the exact location of the type- $\theta$ marginal borrower. The latter borrower is located half-way between banks $j$ and $j+1$.

Solving eq. (4) for $d_{\theta}$ yields:

$$
d_{\theta}\left(r_{\theta}^{j}, r_{\theta}^{j+1}\right)=\frac{1}{2 n}+\frac{p_{\theta}\left(r_{\theta}^{j+1}-r_{\theta}^{j}\right)}{2 \tau_{\theta}}
$$

Bank $j$ faces the following demand for loans: 


$$
L_{\theta}^{j}\left(r_{\theta}^{j}, r_{\theta}^{j+1}\right)=2 d_{\theta}=\frac{1}{n}+\frac{p_{\theta}\left(r_{\theta}^{j+1}-r_{\theta}^{j}\right)}{\tau_{\theta}}
$$

For $\theta=h$, eq. (6) equals to:

$$
L_{h}^{j}\left(r_{h}^{j}, r_{h}^{j+1}\right)=2 d_{h}=\frac{1}{n}+\frac{p_{h}\left(r_{h}^{j+1}-r_{h}^{j}\right)}{\tau_{\theta}}
$$

Correspondingly, for $\theta=l$ :

$$
L_{l}^{j}\left(r_{l}^{j}, r_{l}^{j+1}\right)=2 d_{l}=\frac{1}{n}+\frac{p_{l}\left(r_{l}^{j+1}-r_{l}^{j}\right)}{\tau_{\theta}}
$$

We now turn to consider Stage 1. The optimisation problem of bank $j$ is regarded as choosing the optimal lending rates $r_{h}^{* j}$ and $r_{l}^{* j}$ by appropriately pricing heterogeneous borrowers through the screening mechanism given similar choices of the other banks. Hence, bank $j$ 's expected net returns per unit of loans granted to borrowers with $h$-type and $l$-type projects are:

$$
u_{h}^{j}\left(r_{h}^{j}\right)=q p_{h} r_{h}^{j}-(1+e)
$$

and

$$
u_{l}^{j}\left(r_{l}^{j}\right)=(1-q) p_{l} r_{l}^{j}-(1+e)
$$

Bank $j$ solves the following maximisation problem:

$$
\max _{r_{h}^{j}, r_{l}^{j}} \pi^{j}=u_{h}^{j}\left(r_{h}^{h}\right) L_{h}^{j}\left(r_{h}^{j}, r_{h}^{j+1}\right)+u_{l}^{j}\left(r_{l}^{j}\right) L_{l}^{j}\left(r_{l}^{j}, r_{l}^{j+1}\right)
$$

Substituting eqs. (6a), (6b), (7a), and (7b) into eq. (8), we get: 


$$
\begin{aligned}
\max _{r_{h}^{j}, r_{l}^{j}} \pi^{j}= & {\left[q p_{h} r_{h}^{j}-(1+e)\right]\left[\frac{1}{n}+\frac{p_{h}\left(r_{h}^{j+1}-r_{h}^{j}\right)}{\tau_{\theta}}\right] } \\
& +\left[(1-q) p_{l} r_{l}^{j}-(1+e)\right]\left[\frac{1}{n}+\frac{p_{l}\left(r_{l}^{j+1}-r_{l}^{j}\right)}{\tau_{\theta}}\right]
\end{aligned}
$$

We differentiate the profit function with respect to $r_{h}^{j}$ and $r_{l}^{j}$. The symmetric price equilibrium is obtained by setting $r_{h}^{j}=r_{h}^{j+1}$ and $r_{l}^{j}=r_{l}^{j+1}$ (the proof is relegated to the Appendix):

$$
\begin{aligned}
& r_{h}^{* j}=\frac{1}{p_{h}}\left[\frac{\tau_{h}}{n}+\frac{(1+e)}{q}\right], \text { when } \theta=h \\
& r_{l}^{* j}=\frac{1}{p_{l}}\left[\frac{\tau_{l}}{n}+\frac{(1+e)}{(1-q)}\right], \text { when } \theta=l
\end{aligned}
$$

Eq. (10a) is written as follows:

$r_{h}^{* j}=\frac{\tau_{h}}{n p_{h}}+\frac{(1+e)}{q p_{h}} \Leftrightarrow r^{* j}=\frac{\tau_{h} q+n+n e}{n q p_{h}} \Leftrightarrow n(1+e)=n q p_{h} r^{* j}{ }_{h}-\tau_{h} q \Leftrightarrow e=q p_{h} r^{* j}{ }_{h}-\frac{\tau_{h} q}{n}-1$

Computing the first derivative with respect to $n$, we obtain: $\frac{\partial e}{\partial n}=\frac{\tau_{h} q}{n^{2}}$, which is positive since $\tau_{h} q>0$, and $\tau_{h}, q>0$, by assumption. ${ }^{6}$ This shows that the greater the number of competitors in the market, the larger the screening cost that each competitor incurs. In simple terms, banks invest more in screening technology under mounting competition.

Different interpretations can be placed upon this finding. First, the level of credit risk that banks are subjected to in a more competitive environment tends to be higher. This is because banks are more prone to make mistakes in their lending decisions as the number of credit applicants and, hence, that of applicants with low-quality projects increase due to the intensified competition. To protect their portfolios from the increased threat of credit risk, banks turn to invest a larger amount

\footnotetext{
${ }^{6}$ It is straightforward that we obtain the same result if we differentiate eq. (10b) with respect to $n$ instead of eq. (10a).
} 
of money in screening. Further, if a bank anticipates a reduction in the expected returns from a proposed project due to the higher credit risk, this can produce a pronounced increase in the screening of prospective borrowers, with substantial corresponding welfare effects. ${ }^{7}$

An alternative interpretation of the reported increase in the screening cost due to the enhanced competition is grounded on the view of Acharya et al. (2006) according to which the informational effectiveness of banks is lower in highly competitive markets. Similarly, Shaffer (1998) argues that the screening process is less effective in less concentrated markets, and Gomez and Ponce (2014) show that more vigorous competition deteriorates the effectiveness of banks to screen loan applicants. On the whole, banks are required to incur a higher screening cost under fiercer competition to maintain the quality of the acquired information.

The global financial crisis allowed the banking market to evolve into a system where banks are more effective in screening the would-be borrowers. This hinges upon the Schumpeterian concept of 'creative destruction', which, in the context of our research, refers to the emergence of a new banking market architecture through the devastating effects of the crisis on the sector that allows banks to operate more effectively. To give an example, the majority of banks that failed during the crisis were small-to-medium sized banks; on the other hand, those that were bailed out were large institutions. Moreover, the numerous mergers and acquisitions gave birth to a bunch of new large banks. Since smaller banks have admittedly a more limited access to the information set of loan applicants compared to larger banks, the post-crisis banking sector which consists of a higher number of large banks and a lower number of small banks is more effective in screening. ${ }^{8}$

\section{Conclusion}

Historically, financial crises and the structure of the banking market have been strongly interrelated with each other. In a crisis, the number of distressed institutions increase, and this, in turn, leads to an upsurge in the volume of bankruptcies, liquidations, and consolidations. Consequently, the number of banks in the industry and, hence, the level of competition is drastically reduced.

\footnotetext{
${ }^{7}$ A similar argument had been put forward by Bose et al. (2012).

${ }^{8}$ Marquez (2002) shows that a small bank has less information about the market than a large bank and, hence, the former bank is less effective in its screening.
} 
We demonstrate that when market conditions are distorted, this has a dilutive impact on the incentives mechanism of banks to screen the loan applicants. Indeed, the large-scale transformations that occurred in the banking market led financial institutions to reassess their incentives to invest in screening. More generally, banks are found to invest less in screening technology when competition is eroded. 


\section{References}

Acharya, V.V., Hasan, I., Saunders, A., 2006. Should banks be diversified? Evidence from individual bank loan portfolios. J Business 79, 1355-1412.

Bolton, P., Freixas, X., Gambacorta, L., Mistrulli, P.E., 2013. Relationship and transaction lending in a crisis. Bank for International Settlements Working Papers no 417.

Boot, A.W.A, Thakor, A.V., 2000. Can relationship banking survive competition?. J. Finance 55, 679-713.

Bose, A., Debashis, P., Saapington, D.E.M., 2012. Extreme screening policies. Eur. Econ. Rev. 56, 1607-1620.

Calderon, C., Schaeck, K., 2016. The effects of government interventions in the financial sector on banking competition and the evolution of zombie banks. J. Financ. Quant. Anal. 51, 13911436.

Gomez, F., Ponce, J., 2014. Bank competition and loan quality. J Financ. Serv. Res. 46, 215-233.

Marquez, R., 2002. Competition, adverse selection, and information dispersion in the banking industry. Rev. Financ. Stud. 15, 901-926.

Salop, S.C., 1979. Monopolistic competition with outside goods. Bell J Econ 10, 141-156.

Shaffer, S., 1998. The winner's curse in banking. J. Financ. Intermed. 7, 359-392. 


\section{Appendix}

Eq. (9) can be written as follows:

$$
\begin{aligned}
\max _{r_{h}^{j}, r_{l}^{j}} \pi^{j}= & \frac{q p_{h} r_{h}^{j}}{n}+\frac{q p_{h}^{2} r_{h}^{j} r_{h}^{j+1}-q p_{h}^{2}\left(r_{h}^{j}\right)^{2}}{\tau_{h}}-\frac{1}{n}-\frac{p_{h} r_{h}^{j+1}-p_{h} r_{h}^{j}}{\tau_{h}}- \\
& -\frac{e}{n}-\frac{e p_{h} r_{h}^{j+1}+e p_{h} r_{h}^{j}}{\tau_{h}}+\frac{p_{l} r_{l}^{j}}{n}+\frac{p_{l}^{2} r_{l}^{j} r_{l}^{j+1}-p_{l}^{2}\left(r_{l}^{j}\right)^{2}}{\tau_{l}}- \\
& -\frac{q p_{l} r_{l}^{j}}{n}-\frac{q p_{l}^{2} r_{l}^{j} r_{l}^{j+1}+q p_{l}^{2}\left(r_{l}^{j}\right)^{2}}{\tau_{l}}-\frac{1}{n}-\frac{p_{l} r_{l}^{j+1}+p_{l} r_{l}^{j}}{\tau_{l}}- \\
& -\frac{e}{n}-\frac{e p_{l} r_{l}^{j+1}+e p_{l} r_{l}^{j}}{\tau_{l}}
\end{aligned}
$$

To obtain bank j's optimal loan interest rate for the $h$-type borrowers, we calculate the first order conditions of (A1) with respect to $r_{h}^{j}$ :

$$
\begin{gathered}
\frac{\partial \pi^{j}\left(r^{j}, r^{j+1}\right)}{\partial r_{h}^{j}}=0 \Rightarrow \frac{q p_{h}}{n}+\frac{q p_{h}^{2} r_{h}^{j+1}-2 q p_{h}^{2} r_{h}^{j}}{\tau_{h}}+\frac{p_{h}}{\tau_{h}}+\frac{e p_{h}}{\tau_{h}}=0 \Leftrightarrow \\
\Leftrightarrow \tau_{h} q+n q p_{h} r_{h}^{j+1}-2 n q p_{h} r_{h}^{j}+n+n e=0
\end{gathered}
$$

To obtain the symmetric Nash equilibrium, we set $r_{h}^{j}=r_{h}^{j+1}$ :

$$
n q p_{h} r_{h}^{j}=\tau_{h} q+n(1+e) \Leftrightarrow r_{h}^{j}=\frac{\tau_{h}}{n p_{h}}+\frac{(1+e)}{q p_{h}} \Leftrightarrow r_{h}^{j}=\frac{1}{p_{h}}\left[\frac{\tau_{h}}{n}+\frac{(1+e)}{q}\right]
$$

We work in a similar way to get the optimal loan rate for the $l$-type borrowers:

$$
\begin{aligned}
\frac{\partial \pi^{j}\left(r^{j}, r^{j+1}\right)}{\partial r_{l}^{j}}= & 0 \Rightarrow \frac{p_{l}}{n}+\frac{p_{l}^{2} r_{l}^{j+1}-2 p_{l}^{2} r_{l}^{j}}{\tau_{l}}-\frac{q p_{l}}{n}-\frac{q p_{l}^{2} r_{l}^{j+1}+2 q p_{l}^{2} r_{l}^{j}}{\tau_{l}}+\frac{p_{l}}{\tau_{l}}+\frac{e p_{l}}{\tau_{l}}=0 \Leftrightarrow \\
& \Leftrightarrow \tau_{l}+n p_{l} r_{l}^{j+1}-2 n p_{l} r_{l}^{j}-\tau_{l} q-n q p_{l} r_{l}^{j+1}+2 n q p_{l} r_{l}^{j}+n+n e=0
\end{aligned}
$$


We now set $r_{l}^{j}=r_{l}^{j+1}$ :

$$
n p_{l} r_{l}^{j}-n q p_{l} r_{l}^{j}=\tau_{l}(1-q)+n(1+e) \Leftrightarrow r_{l}^{j}=\frac{t_{l}}{n p_{l}}+\frac{(1+e)}{p_{l}(1-q)} \Leftrightarrow r_{l}^{j}=\frac{1}{p_{l}}\left[\frac{\tau_{l}}{n}+\frac{(1+e)}{(1-q)}\right]
$$

